\title{
Loss of miR-494 by exosomes promotes melanoma proliferationer and metastasis
}

\author{
Jingjing Li ${ }^{1}$, Jia Chen ${ }^{1}$, Shaohua Wang ${ }^{1}$, Ping Li ${ }^{1}$, Changli Zheng ${ }^{2}$, Shijie Tang ${ }^{3}$, \\ Xiao Zhou ${ }^{4}$, Yongguang $\mathrm{Tao}^{5}$, Xiang Chen ${ }^{6}$, Lichun Sun ${ }^{7}$, Aijun Wang ${ }^{8}$, Ke $\mathrm{Cao}^{9}$ and \\ Jianda Zhou ${ }^{1}$ \\ ${ }^{1}$ Department of Plastic Surgery of Third Xiangya Hospital, Central South University, Changsha, China \\ ${ }^{2}$ Department of Pathology of Xiangya Hospital and School of Basic Medical Science, Central South University, Changsha, \\ China \\ ${ }^{3}$ Department of Plastic Surgery, Second Hospital of Shantou University, Shantou, China \\ ${ }^{4}$ Department of Head and Neck Surgery, Department of Oncology Plastic Surgery, Hunan Province Cancer Hospital, The \\ Affiliated Hospital of Xiangya School of Medicine, Central South University, Changsha, China \\ ${ }^{5}$ Cancer Research Institute, School of Basic Medical Science, Central South University, Changsha, China \\ ${ }^{6}$ Department of Dermatology of Xiangya Hospital, Central South University, Changsha, China \\ ${ }^{7}$ Medicine School of Medicine Tulane University Health Science Center, New Orleans, LA, USA \\ ${ }^{8}$ Surgical Bioengineering Laboratory, Department of Surgery, UC Davis School of Medicine, Sacramento, CA, USA \\ ${ }^{9}$ Department of Oncology of Third Xiangya Hospital, Central South University, Changsha, China \\ Correspondence to: Jianda Zhou, email: zhoujianda@csu.edu.cn \\ Ke Cao, email: csucaoke@163.com
}

Keywords: exosome; melanoma; miR-494; apoptosis; metastasis

Received: September 01,2017 Accepted: December 04, $2017 \quad$ Published: January 02, 2018

Copyright: Li et al. This is an open-access article distributed under the terms of the Creative Commons Attribution License 3.0 (CC BY 3.0), which permits unrestricted use, distribution, and reproduction in any medium, provided the original author and source are credited.

\section{ABSTRACT}

Previous studies have established that exosomes involve material transport in melanoma. However, the detail molecular mechanisms remain to be elucidated. Here, we aimed to determine the functions of exosome-derived miR-494 in melanoma progress. In this study, we firstly found significantly higher levels of miR-494 in melanoma patients' serum exosomes. miR-494 was upregulated in high-metastaic melanoma cell exosomes while downregulated in cell itself.. Functional studies revealed that decrease exosome production and overexpression of miR-494 significantly inhibited cancer cells proliferation, migration and invasion in vitro. Nude mice experiments confirmed that upregulation miR-494 suppressed tumor growth and metastasis by inhibiting exosomes release in vivo. In conclusion, Exosomal transfer of miR-494 is an alternative modality in the treatment of melanoma.

\section{INTRODUCTION}

Malignant melanoma (MM) is one of the aggressive skin cancers with a high mortality rate despite its improvements in diagnostic and therapeutic technology [1-3]. Although great advance has been achieved in the early diagnosis and treatment, the prognosis of $\mathrm{MM}$ paitents remains very poor $[4,5]$. Tumor overgrowth and metastasis are two of the most important hallmarks of malignant tumors, and metastasis is the major cause of tumor recurrence and patient death [6]. Therefore, understanding the underlying molecular pathways involve in the process of tumor growth and metastasis is crucial.

MicroRNAs (miRNAs) regulate gene expression by inhibiting gene translation or facilitating mRNA degradation [7, 8]. In recent years, accumulating evidence has revealed that miRNAs function as tumor suppressors or promoters. In our previous study, we confirmed that miR-33a, miR-199a, miR-18b, and miR-138 function as tumor suppressors by targeting oncogenes in melanoma 
[9-12]. We interestingly found that miR-494 was abnormal low expression in melanoma cell than that in melanocytes via analyzing gene microarray results from Gene Expression Omnibus (GEO) datasets, suggesting miR-494 may play important role in melanoma progress. However, our preliminary experiments revealed that miR-494 was elevated in melanoma patient's serum. Therefore, exact function of miR-494 in melanoma and the underlying mechanism of abnormal expression levels remain largely unclear.

Exosomes are extracellularvesicles that formed at the plasma membrane. They have an average diameter of 40-110 nm. Exosomes are enriched with endosomeassociated proteins, such as CD63, CD9, TSG101 and CD81 $[13,14]$. The endocytosis of exosomes by their target cells results in the intracellular release of vesicular contents, including messenger RNA, miRNA, proteins and lipids [15]. The exosomes have been shown to have pro-tumor properties. For example, cancer-associated adipocytes (CAAs) and fibroblasts (CAFs) exosomes transfer miRNA-21 to the cancer cells, whichsuppressed ovarian cancer apoptosis and confered chemoresistance by binding to APAF1 [16]. Recent studies have explored potential roles for melanoma-derived exosomes in the pathogenesis of proliferation and invasion [17-19]. We found that miR-494 has higher levels in melanoma exosomes and lower levels in the original cells by further analyzing the gene microarray results from GEO datasets. Above mentioned findings strongly suggest that loss of miR-494 may caused by exosomal vesicles. However, the relationship between exosome-derived miR-494 and melanoma tumorigenesis has not been previously reported.

We firstly found miR-494 had significantly different expression level in intracellular and extracellular environment of melanoma. Here, we aimed to determine the detail functions of exosome-derived miR-494 in melanoma progress and identify the molecular mechanisms of miR-494 loss.

\section{RESULTS}

\section{Melanoma serum and cell exosomes have higher miR-494 copy number}

We first profiled differentially expressed genes in A375 cell exosomes (GSM867222, GSM867223) and A375 cells (GSM867220, GSM867221) by analyzing GEO datasets. We found miR-494 upregulated in exosomes (Figure 1A). Interestingly, high expression of miR-494 was also observed in A375 cell exosomes when compared with human melanocytes (HM)exosomes (A375 EX: GSM867222, GSM867223 vs HM EX: GSM867226).

In order to verify the microRNA microarray results of previous GEO datasets analysis, we collected 15 case of melanoma patients' serum and 15 case of normal human serum. Ultracentrifugation was performed to isolate the exosomes. The results of transmission electron microscopy (TEM) and nanoparticle tracking analysis (NTA) revealed that extracellular vesicles derived from MM patients' serum were of the expected exosomal shape (Figure 1B) and size (Figure 1C). The purified exosomes displayed as small round vesicles with a diameter ranging from 60 to $110 \mathrm{~nm}$. WB confirmed that these vesicles expressed the exosomal markers CD9, CD63 and TSG101 (Figure 1D). qRT-PCR method was used to detect miR-494 expression in serum exosomes. The experimental results showed that the miR-494 expression level in MM serum exosomes was significantly higher than that in the normal person serum exosomes (Figure 1E).

\section{Exosomal transfer regulates miR-494 expression}

For verifying the abnormal expression of miR-494 in melanoma cells, qRT-PCR was used to measure miR494 expression levels in primary melanocytes (HEMaLP) and melanoma cell lines with different metastatic potentials. As expected, higher expression level of miR494 was observed in in HEMa-LP cells compared with that in melanoma cell lines WM35, WM451, and A375 (Figure 2A), whereas lower in HEMa-LP exosomes than in melanoma cell exosomes (Figure 2B).

To further explore the biological functions of exosomes in melanoma cells, released exosomes were added into the original productive cell culture medium. The TEM (Figure 2C), western blots (Figure 2D) and NTA (Figure 2E) results confirmed that exosomes (green fluorescence-labeled) were successfully isolatedfrom A375 and WM35 cells, respectively. After $24 \mathrm{~h}$, confocal microscopy was used to examine whether exosomes were absorbed by A375 and WM35 cells, as evidenced by localization of phalloidine and DAPI. As shown in Figure 2F, exosomes were obviously uptaked by melanoma cells. Using PCR, we found miR-494 levels varied according to uptake of different cell exosomes. miR-494 expression notably up-regulated by about 5 folds through being incubated with A375-derived exosomes, whereas had no obvious change with WM35derived exosomes (Figure 2E). These findings indicated that exosmal miR-494 may be tightly associated with the metastatic phenotype of malignant melanoma.

\section{Inhibiting release of exosomal miR-494 suppresses MM cell viability, migration and invasion}

Previous published reports indicate that rab27a plays an important role in exosome biogenesis, which is a small molecular weight GTPase. Three shRNA (small hairpin RNA) expression plasmids targeting rab27a were constructed. Western blotting was performed to detect the expression of rab27a in cells as well as CD63, CD9 and TSG101 protein in isolated vesicles (Figure 3A).Western 
blotting results revealed that the third shRNA sequence had the best inhibitory effect of exosome production, sh3-rab27a plasmid was chose for further investigation. We constructed the miR-494 overexpressing lentivirus vector and anti-miR-494 lentiviral expression vectors, respectively. All above mentioned recombinant plasmids were transfected or co-transfected into A375 and WM35 cells. qRT-PCR results showed that elevating miR494 expression was caused by transfection miR-494 overexpressing alone, sh3-rab27a plasmids alone or both together in A375 cells (Figure 3B, left panel). and, For WM35 cells, knockdown miR-494 only appeared in the
A

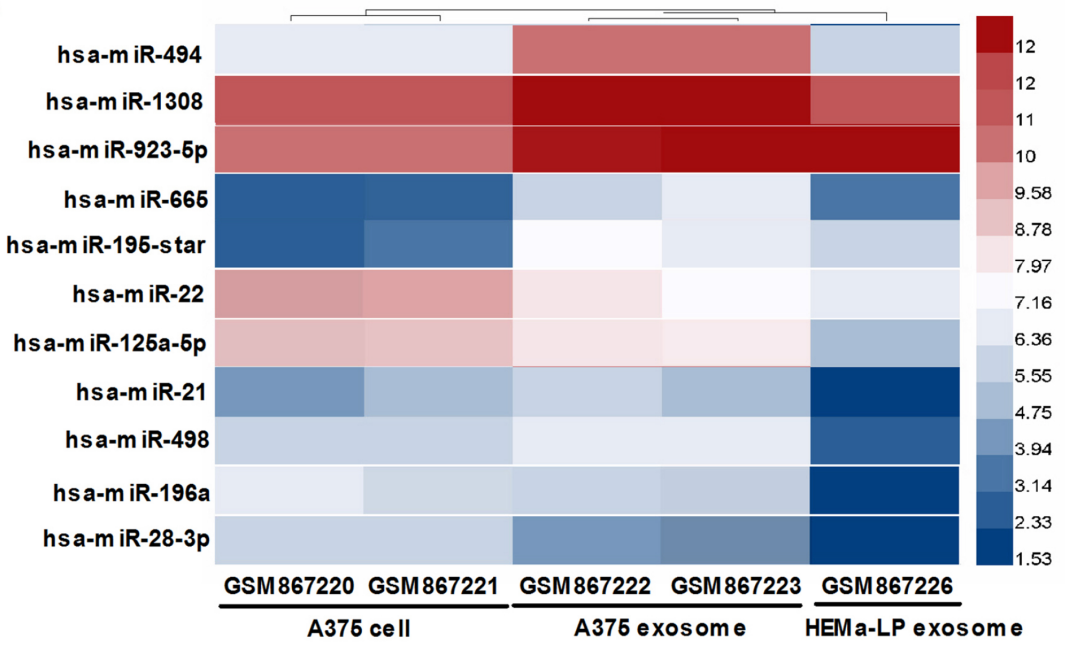

C

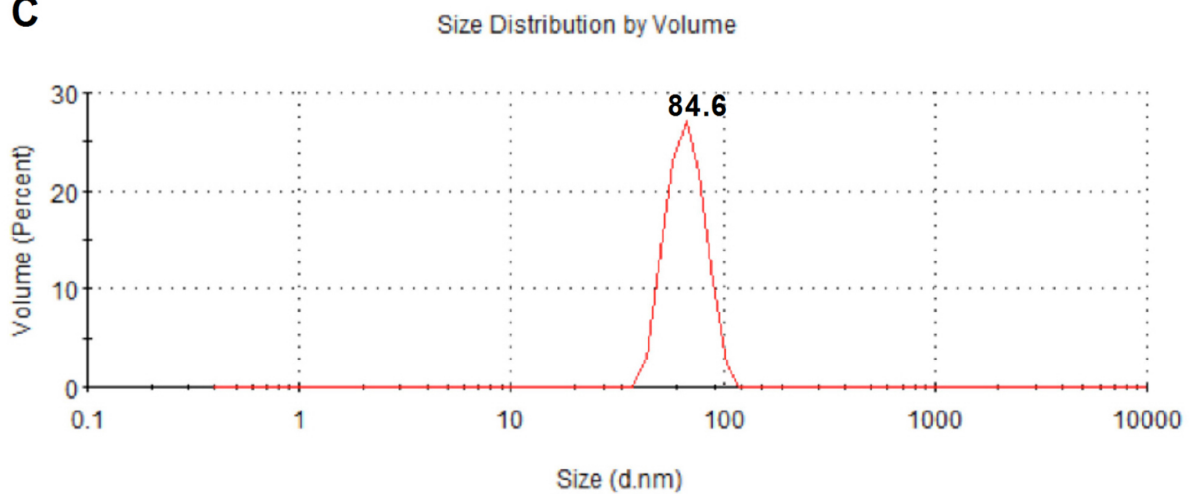

B
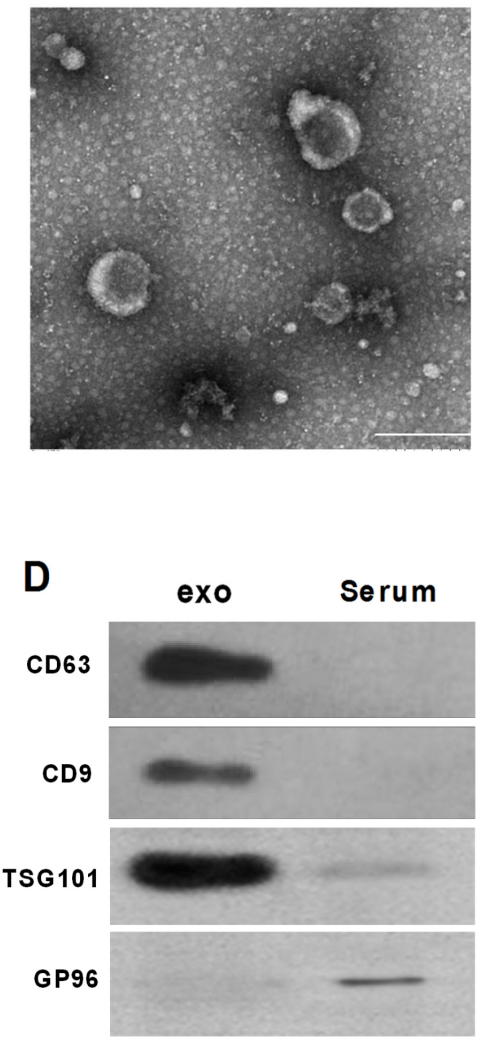

E

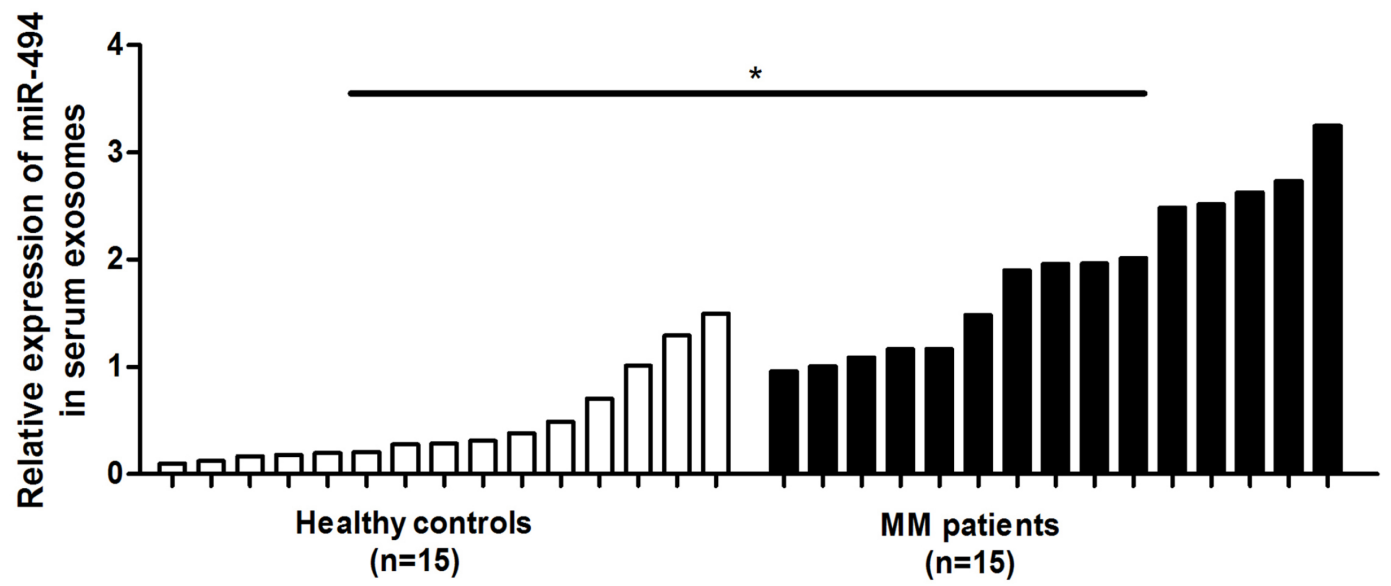

Figure 1: Increased miR-494 expression in MM serum exosomes. (A) The heat map showing the relative expression of miRNAs in from A375 exosomes, A375 cells and HEMa-LP exosomes. (B) Electron micrograph showing "cup-shaped" vesicles, isolated from MM serum. Scale bar, $200 \mathrm{~nm}$. (C) Curve graph showing the particle diameter (nm) of the population of small vesicles. (D) Western blot analysis showing exosome marker CD63, CD9 and TSG101 in the exosome-enriched PBS but not in the plasma, GP96 is one of endoplasmic reticulum (ER) protein used as a negative marker. (E) The relative expression levels of miR-494 in the exosomes was normalized with U6. ${ }^{*} P<0.05$. 
groups which treatment with anti-miR-494 plasmids. Inhibition of exosome release by rab27-deficiency did not significantly alter miR-494 expression (Figure 3B, right panel). And, it implies that melanoma cells excrete miR494 via exosome vesicles, which may mainly happen in high-metastatic cells.

To determine whether exosomal miR-494 suppress tumor developement in MM cells, the effects of exosomal miR-494 on cell viability was examined. Cell viability was determined by using MTT assay kit (Figure 3C). Indeed, the A375 cells showed significantly lower viability after treatment with miR-494 overexpressing plasmids, and reducing the exosome release obviously enhanced this inhibitory effect (Figure 3C, left panel). Conversely, higher cell viability was observed when silenced miR-494 in WM35 cells. Interestingly, we found that exosome released miR-494 level had no significant influence on the WM35 cell proliferation (NC vs. sh3rab27, $P>0.05$; anti-miR-494 vs. anti-miR-494+sh3rab27, $P>0.05)$.

To verify the possible role of miR-494 in MM metastasis, the effects of exosomal miR-494 on the
A

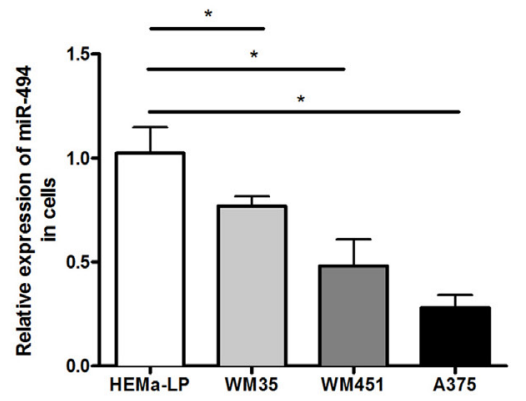

B

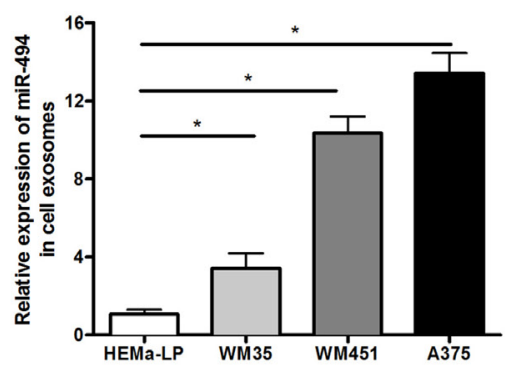

C

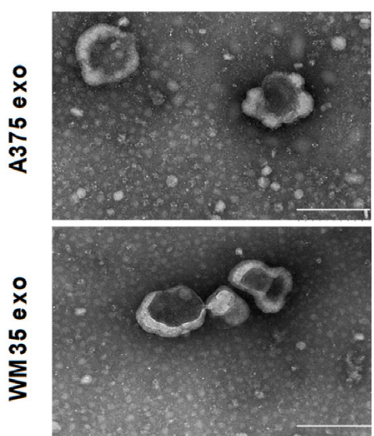

D
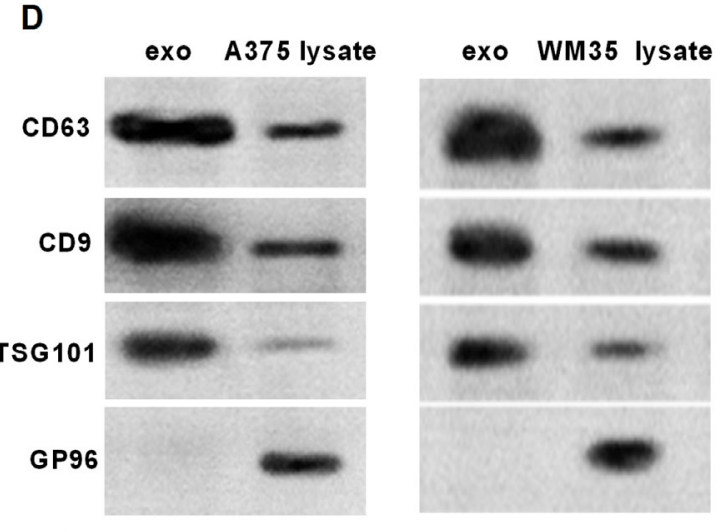

E
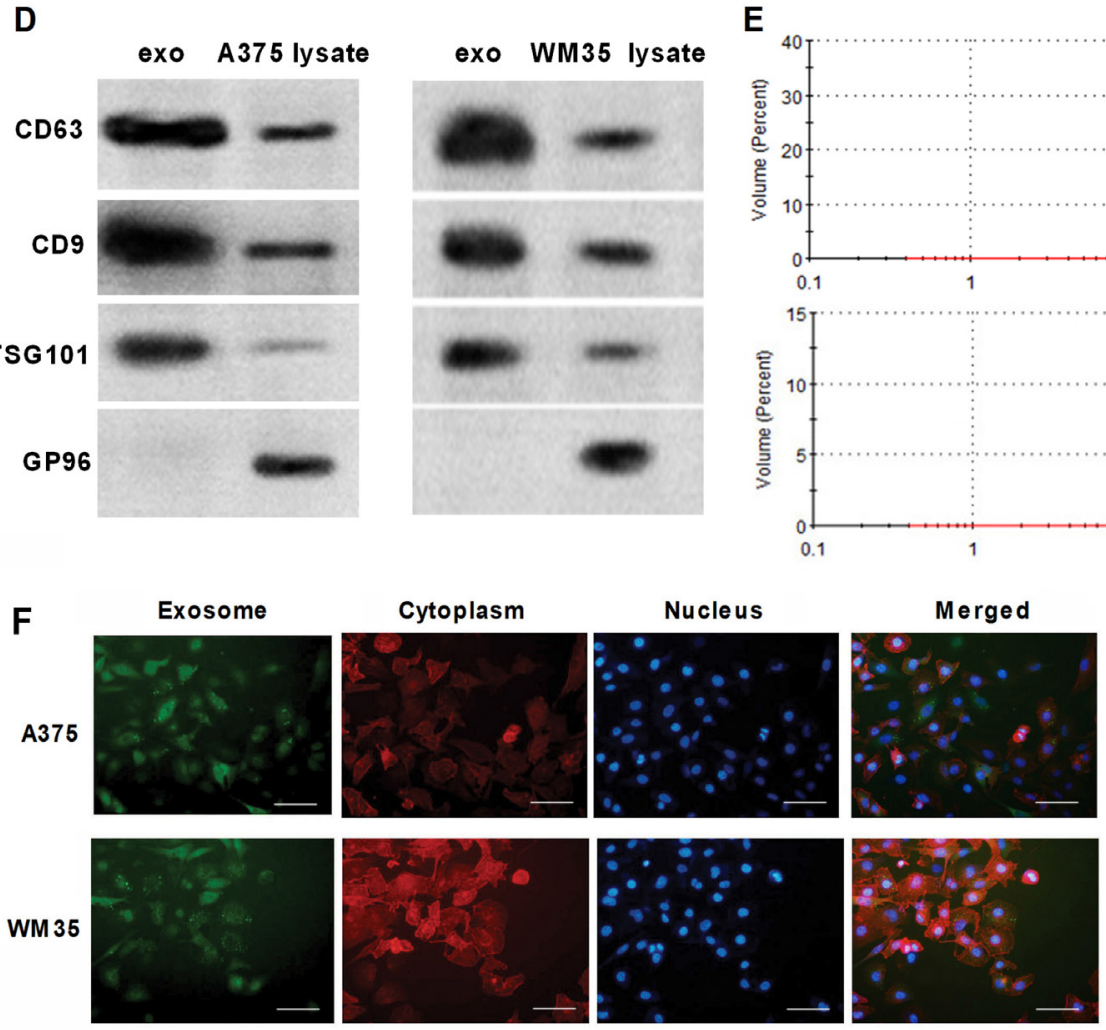

Figure 2: Exosomesregulate miR-494 expression in melanoma cells. (A) qRT-PCR method was used to detect the miR-494 expression levels in HEMa-LP and MM cells. (B) qRT-PCR detects the expression level of miR-494 in exosomes form HEMa-LP and MM exosomes. (C) Electron micrograph showing whole-mount exosomes isolated from MM serum exosomes. Scale bar, $200 \mathrm{~nm}$. (D) Exosome marker CD63, CD9 and TSG101 were observed while GP96 was negative in extractive vesicles. (E) NTA results showing the particle diameter $(\mathrm{nm})$ of the population of small vesicles. (F) Enriched exosomes labeled by green fluorescence were incubated with their original cells for $24 \mathrm{~h}$, such as A375 or WM35 cells. The control cells were treated with equivoluminal normal saline. Fluorescence microscopy was used to detect the fluorescent signals. Scale bar, $200 \mu \mathrm{m}$. (G) qRT-PCR was used to determine the relative miR-494 expression level in cells after being incubated with exosomes or normal saline. NS: normal saline. ${ }^{*} P<0.05$. 
migration and invasion were analyzed in vitro. The results of scratch assay showed that the gap in the miR-494 group is much greater when compared to the control group, and reduce the exosomal miR-494 release obviously enhanced the inhibitory effect in A375 cells (Figure 4A).

A

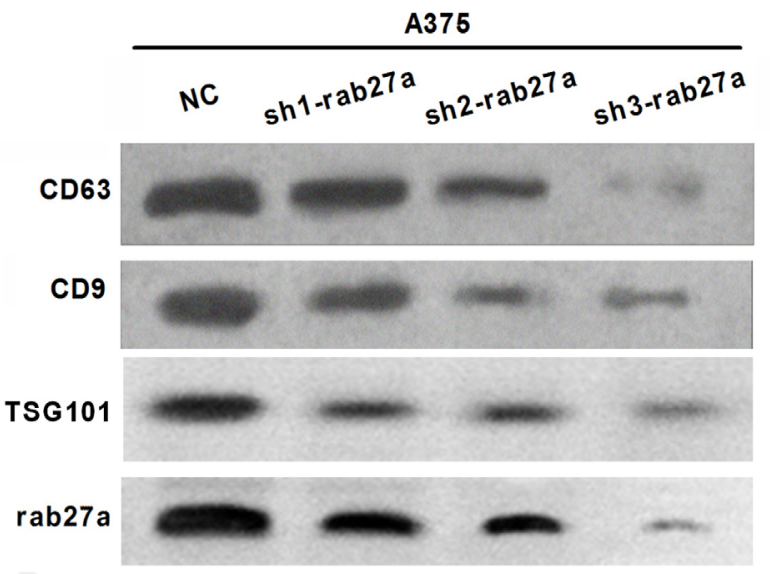

B

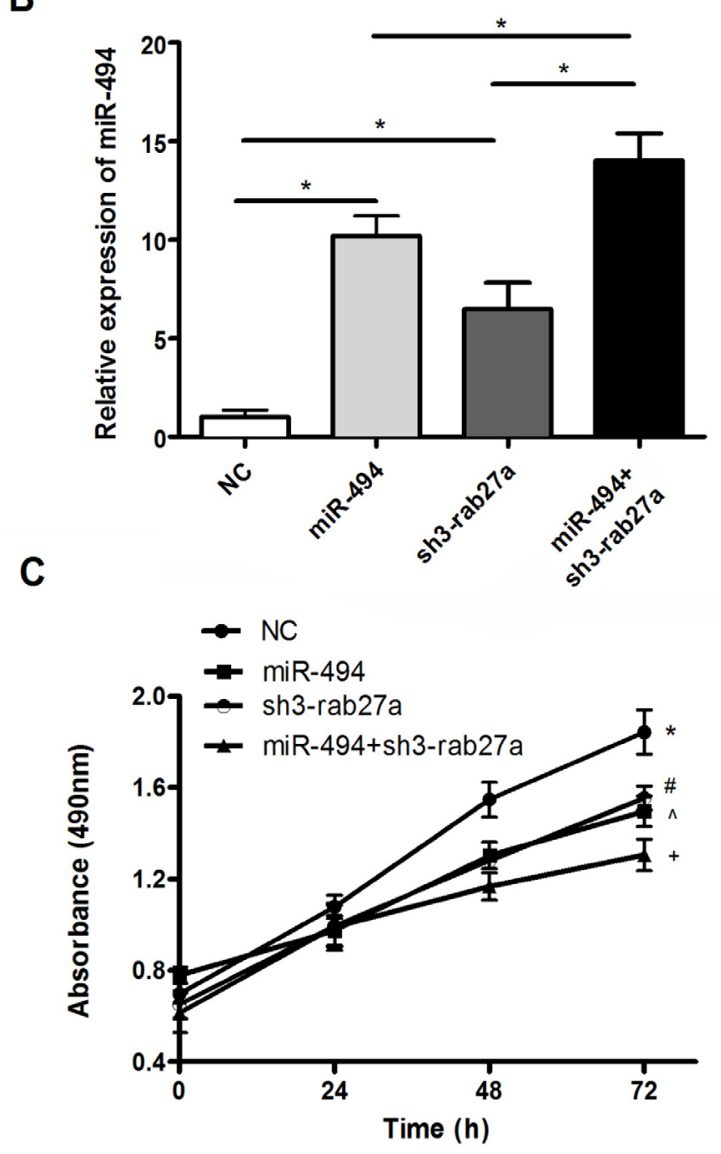

The migration rate of WM35 cells was increased after down-regulation miR-494 (Figure 4B). The Transwell invasion assays were also performed to explore the effects on invasive capacity. As expected, the number of invading cells in the overexpressing miR-494 group and
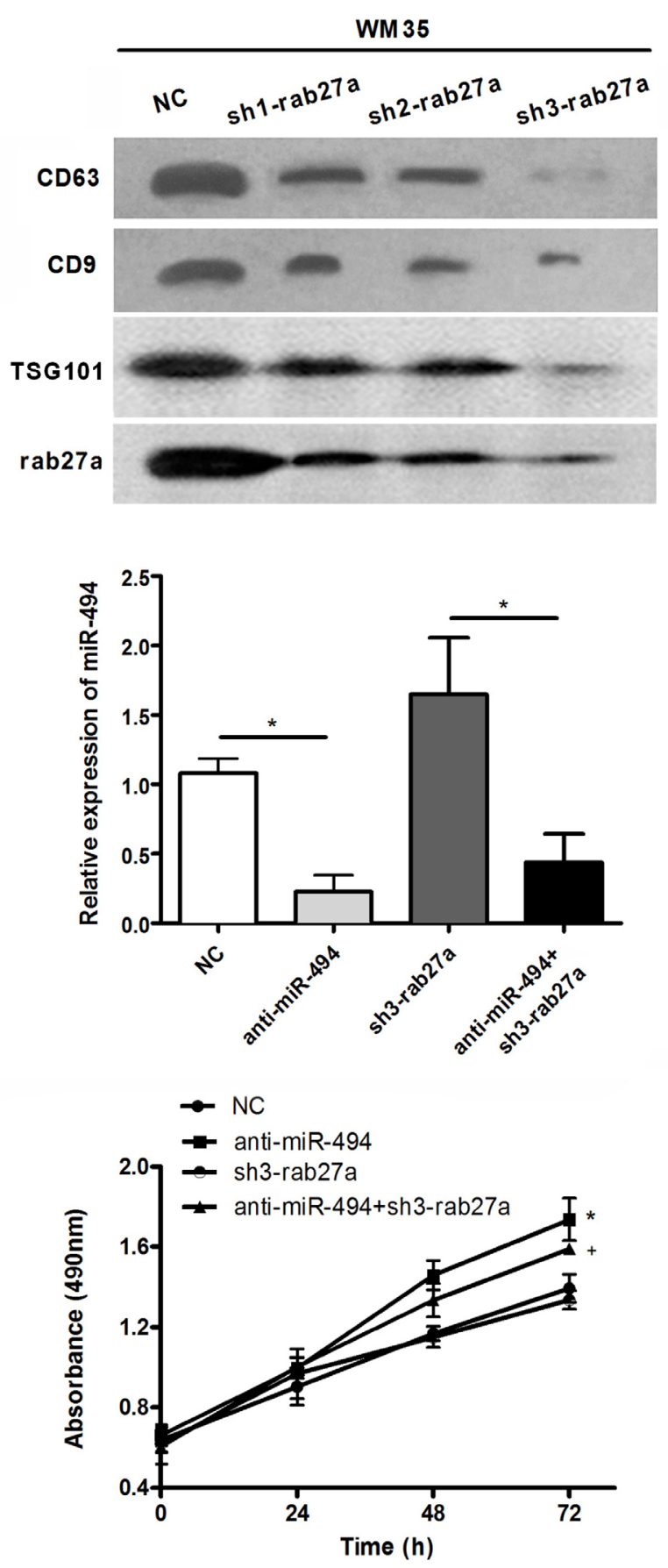

Figure 3: Exosomal miR-494 inhibits MM proliferation. (A) Three shRNA expression plasmids targeting rab27a were transfected into A375 or WM35 cells, respectively. Western blotting results revealed that the third shRNA sequence had the best inhibitory effect of exosomal release. CD63, CD9 and TSG101 were detected in supernatant extracts, while rab27 were measured in total protein extracted from cells. (B) Validate the interference effect of miR-494 in rab27-defecient cells (A375: left panel; WM35: right panel) by qRT-PCR. (C) MTT method was used to detect cell proliferation at specific time points. ${ }^{*} P<0.05$ (NC vs. miR-494 or NC vs. anti-miR-494), ${ }^{+} P<$ 0.05 (sh3-rab27a vs. sh3-rab27a+miR-494 or sh3-rab27a vs. sh3-rab27a+anti miR-494), ${ }^{\#} P<0.05$ (NC vs. sh3-rab27a), ${ }^{\wedge} P<0.05$ (miR494 vs. sh3-rab27a+ miR-494). ${ }^{*} P<0.05$. 
rab27-deficient group was much lower than this number in the NC group (Figure 4C), whereas the invading cells were higher in anti-miR-494 group (Figure 4D). In short, exosomal miR-494 significantly inhibited invasion and migration in high-metastatic cell limes, indicating that it suppressed metastasis in melanoma.

\section{Exosomal miR-494 functions as tumor suppressor via promoting cell apoptosis}

Previous research proved miR-494 mainly suppresses Bcl-2 in several malignant tumor [20]. Bcl2 is considered as a key factor of the apoptotic process of tumor cells. Flow cytometer was performed to detect the apoptosis. Co-transfection of sh3-rab27a and miR-494 signifcantly increased the percentage of cell apoptosis in A375 (Figure 5A, 5E). For WM35 cells, knockdown miR-
494 accompanied by lower cell apoptosis (Figure 5B, 5E). Western blotting was also performed to analyze the expression of Bcl-2 protein. As indicated in Figure 5C, $5 \mathrm{~F}$ compared with $\mathrm{NC}$ cells, significantly decreased $\mathrm{Bcl} 2$ expression was detected in A375-miR-494 and A375-sh3-rab27a cells, while increased in WM35-antimiR-494 (Figure 5D, 5F). These results indicated Bcl-2 is one downstream molecular target for the antioncogenic function of exosomal miR-494.

\section{Inhibiting release of exosomal miR-494} suppresses MM growth and metastasis in nude mice

To confirm the effects of exosomal miR-494 in vivo, Nude mice were subcutaneously inoculated human melanoma A375 cells. Mice were injected with A375 cell
A
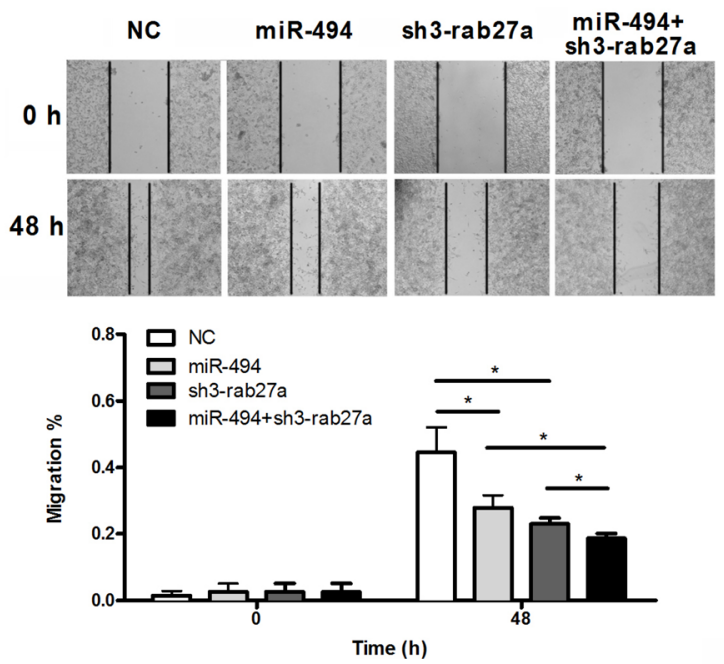

B
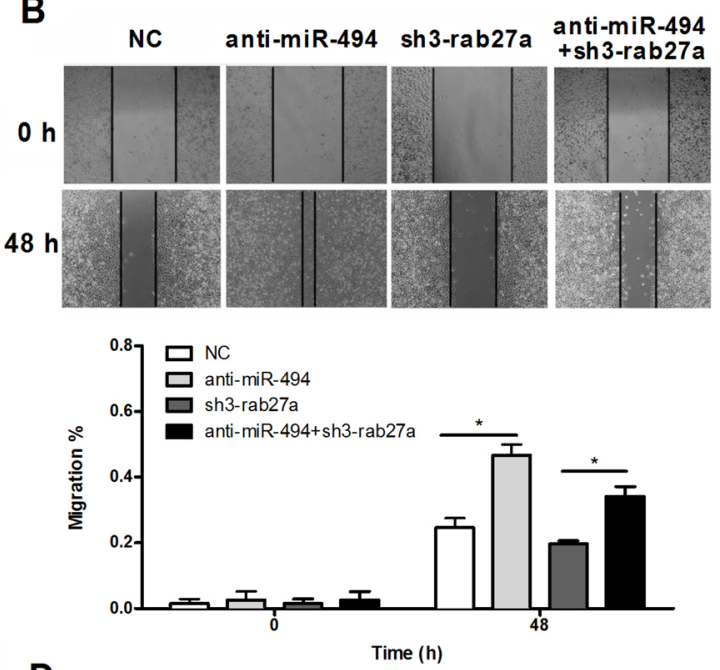

D
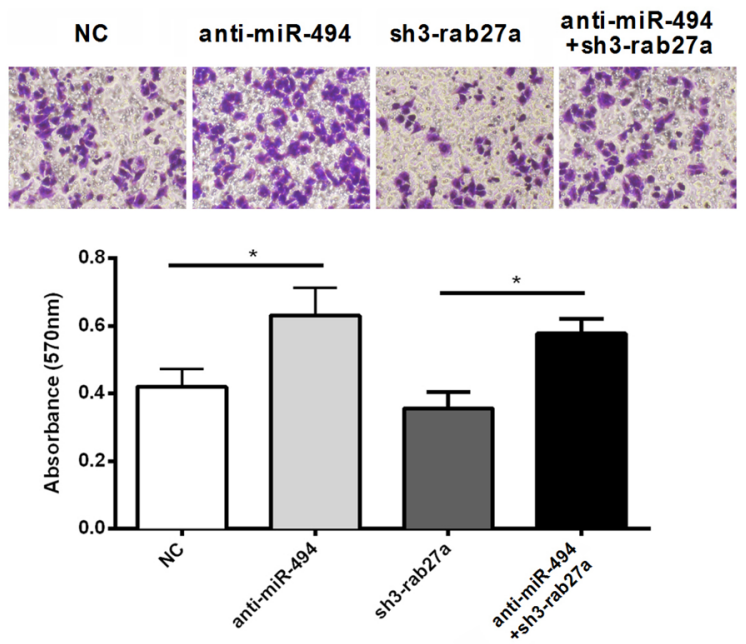

Figure 4: Exosomal miR-494 inhibits MM cell migratory and invasive capacity. Migration of A375 (A) and WM35 (B) cells into the scratched area was monitored at the indicated time points. Representative microscopic images (magnifcation, $\times 40$ ). The migration rate of each group at 0 and $48 \mathrm{~h}$. Representative microscopic images of invasive A375 (C) and WM35 (D) cells from different groups (magnifcation, $\times 200$ ). ${ }^{*} P<0.05$. 
with different treatment. After 42 days, the mice were sacrificed (Figure 6A) to remove tumors (Figure 6B). The average tumor volume in the blank vector group was 1.365 $\pm 0.133 \mathrm{~cm}^{3}$, which was significant higher than that in the miR-494 group, sh3-rab27a group and co-transfection group $\left(0.133 \pm 0.227,0.454 \pm 0.291\right.$ or $0.135 \pm 0.040 \mathrm{~cm}^{3}$, respectively; Figure 6C). The average tumor weight in the blank vector group was $(1.285 \pm 0.099) \mathrm{g}$, which was significantly higher than that in the miR-494, sh3-rab27a group and co-transfection group $(0.816 \pm 0.191,0.398 \pm$ $0.261,0.124 \pm 0.043 \mathrm{~g}$, respectively; Figure $6 \mathrm{D}$ ).

In addition, the effect of exosomal miR-494 on tumor cells apoptosis was tested by TUNEL assay. As shown in Figure 6E, upregulation of miR-494 and suppression exosome release at the same time markedly increased the apoptosis of A375 cells. A375 cells were injected into the tail veins of nude mice and assessed the number of metastasized tumor nodules in the mouse lung. Hematoxylin and eosin (H\&E) staining of paraffinembedded lung tissues also showed a decrease in the size (Figure 6F) of the metastatic foci in mice injected with high miR-494 expression level cells. Exosomal miR494 significantly inhibited the ability of metastasis in melanoma.

\section{DISCUSSION}

Recent studies have shown that in addition to initiation via soluble mediators, cell-cell communication can be initiated through surface interactions between circulating exosomes and transmembrane molecules expressed by target cells [21]. The fusion of exosomes with target cell membranes facilitates the transfer of cell surface molecules and receptors from donor to recipient cells. Furthermore, the endocytosis of exosomes by their target cells results in the intracellular release of vesicular contents, including messenger RNA, microRNA (miRNA), proteins and lipids. Tumor exosomes have been shown to have angiogenic properties. For example, colorectal cancer exosomes transfer mRNAs, which promote endothelial cell proliferation and facilitate angiogenesis [22], whereas glioblastoma-derived exosomes promote tubule formation by recipient endothelial cells [23]. Furthermore, tumour exosomes secrete factors that suppress natural killer cell activity and induce T-cell apoptosis [24].

The transfer of miRNA by exosomes is particularly interesting, because miRNAs are more stable and can control the expression of multiple target genes in the recipient cells. In addition, miRNAs have been shown to
A
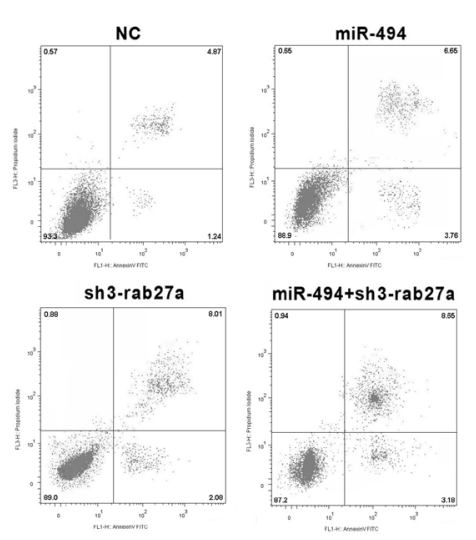

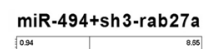

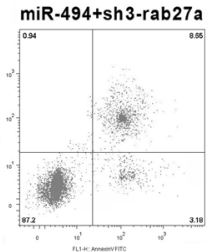

B
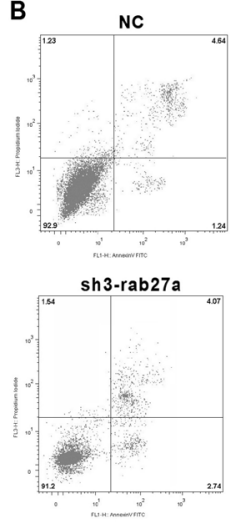

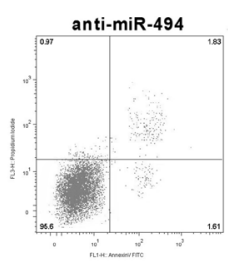

anti-miR-494+sh 3-rab27a
C
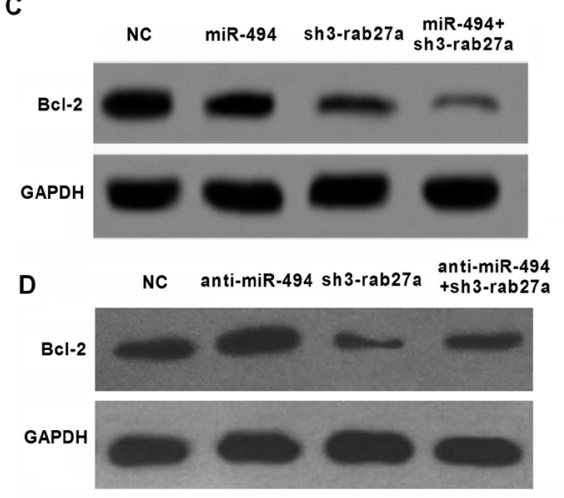

E
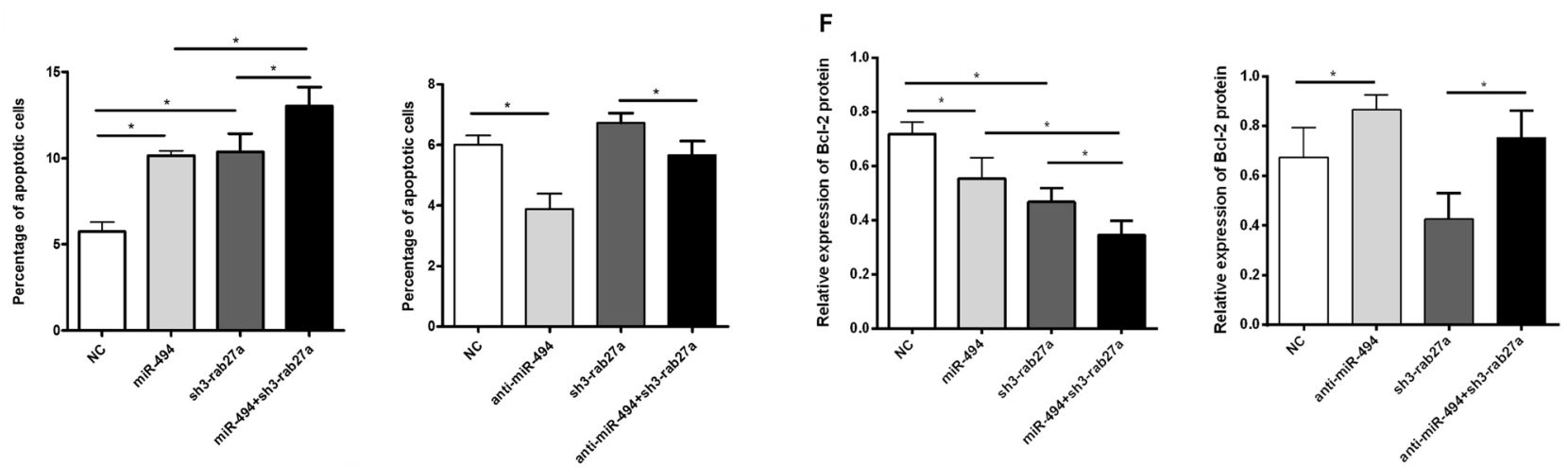

Figure 5: Inhibition of exosomal miR-494 release promotes cell apoptosis. Representative flow cytometry assay of apoptotic cells in A375 (A) and WM35 (B) cells. Annexin V and propidium iodide co-positive representes viable apoptotic cells (right up quadrant). Annexin $\mathrm{V}$ single positive indicates early apoptotic cells (right down quadrant). Bcl-2 protein acts as important apoptosis marker, which was measured by western blot. The Bcl-2 protein express levels were detected in A375 (C) and WM35 (D) cells, respectively. (E) Histograms show the percentage of apoptotic cells in A375 and WM35 cells. (F) The relative expression levels of Bcl-2 normalizing for GAPDH. ${ }^{*} P<0.05$. 
regulate cell differentiation, proliferation and apoptosis, and contribute to the development of multiple tumour types [25-27]. Although the miRNA signatures of tumorderived exosomes have been identified in multiple tumor types, including melanoma, the functional roles of these exosomal miRNAs in modulating the malignant phenotypes have not been elucidated.

A
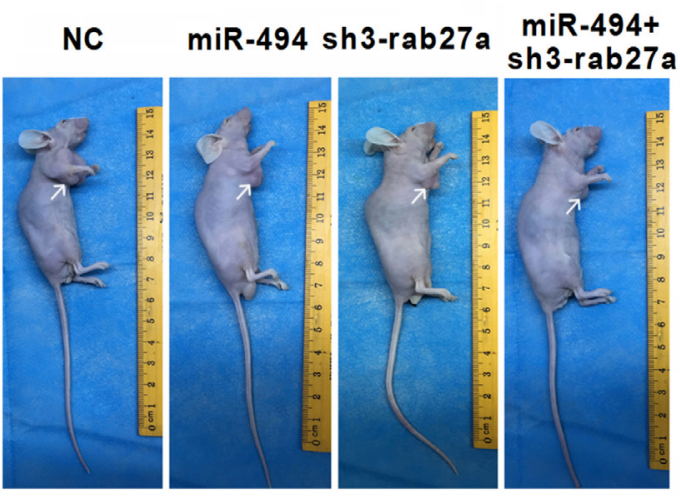

C

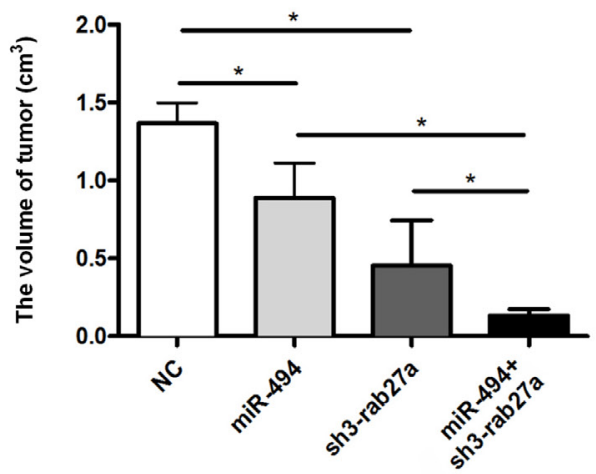

E
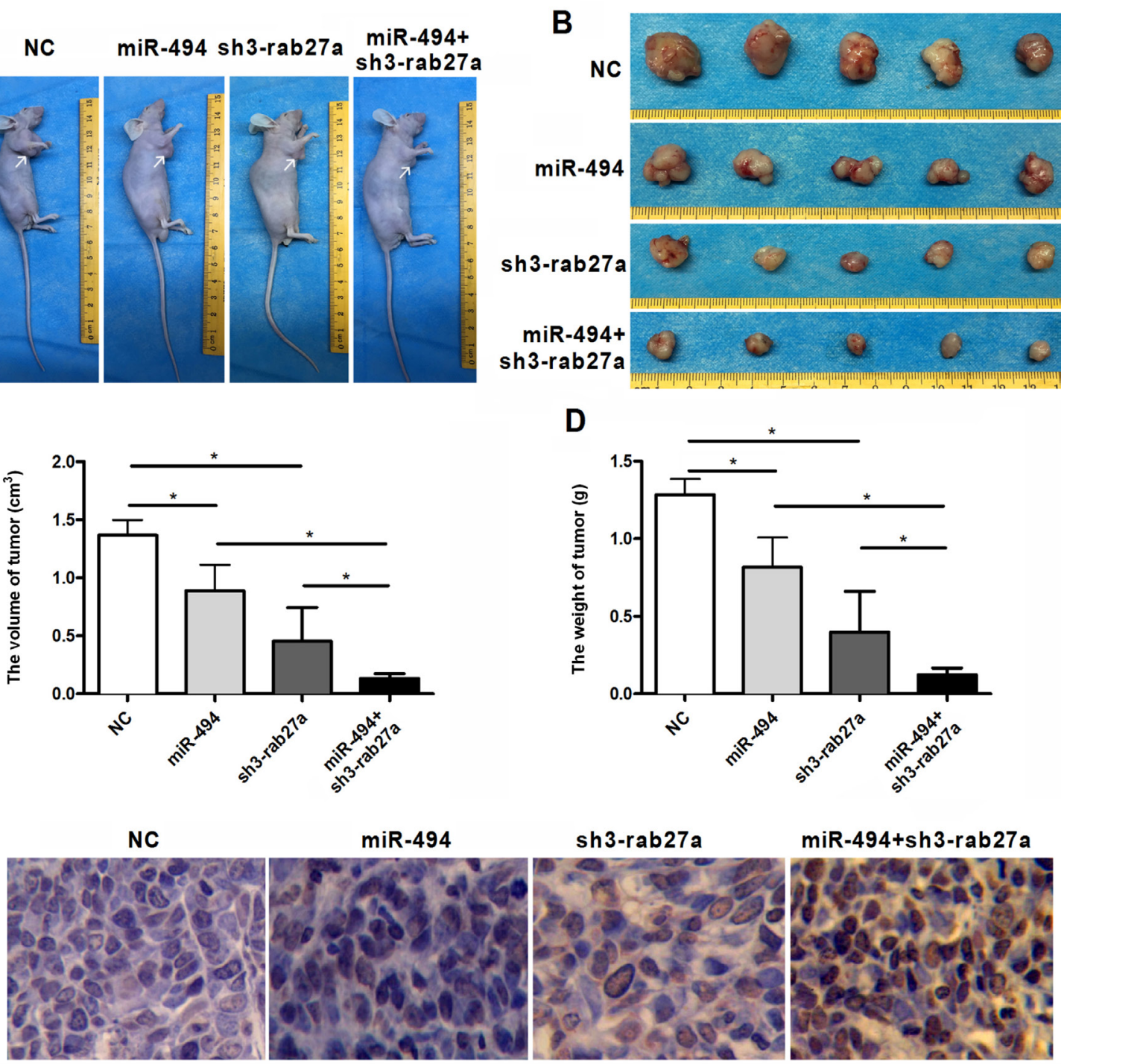

F

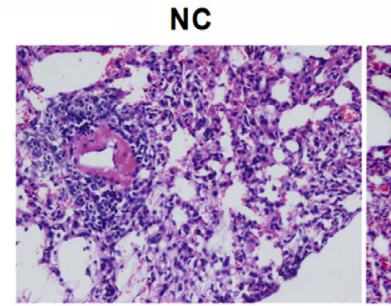

miR-494

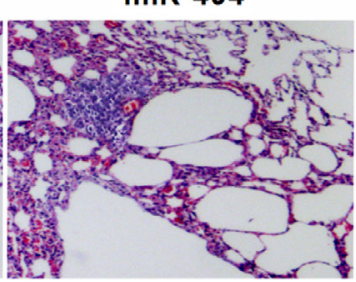

sh3-rab27a

miR-494+sh 3-rab27a
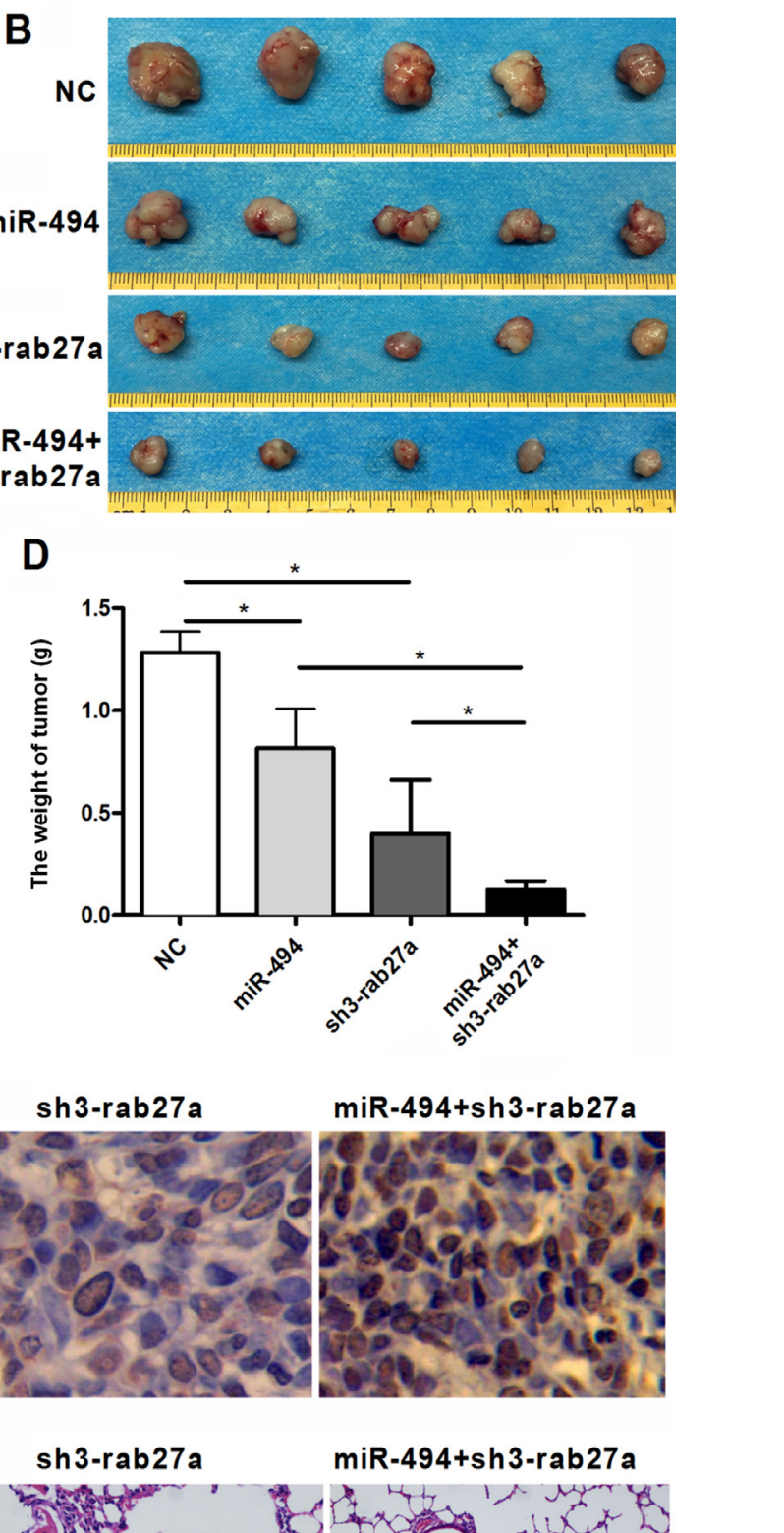
from GEO abundant for the vesicles revealed the expected exosome features. GP96 is one of endoplasmic reticulum (ER) protein, was
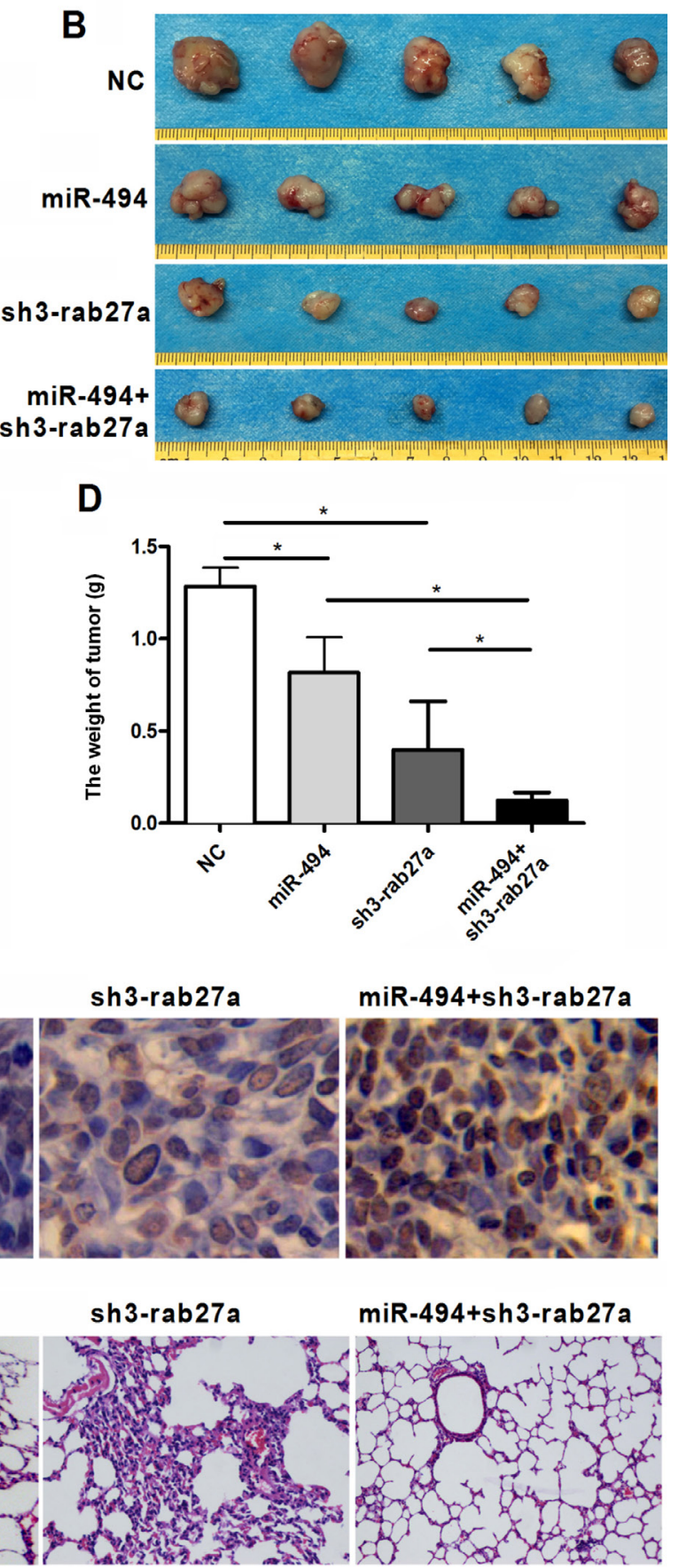

Figure 6: Exosomal miR-494 suppresses tumor growth and metastasis in nude mice. Representative images of sacrificed mice (A) and subcutaneous tumors (B) at day 42. Histograms showing the volume (C) and (D) weight of A375 tumor xenografts in each group. (E) Tumor cells apoptosis was tested by TUNEL assay. (F) Hematoxylin and eosin (H\&E) staining of lung tissues of the metastatic foci in mice. ${ }^{*} P<0.05$. 
negative in the isolated vesicles. Above evidences were reminders that purify exosomes were isolated from A375 and WM35 cells. Furthermore, significantly higher miR494 expression levels were confirmedin both patients' serum exosomes and high-metastic MM cell exosomes by a qRT-PCR analysis.

Additionally, we explored the possible mechanism by which miR-494 may involve in MM. Previous studies have revealed that miR-494 directly target oncogene INPP4B in melanoma [28]. However, the functions of miR-494 and related mechanisms has not yet study. We confirmed that exosome regulated miR-494 expression level in high-metastic MM cells. For primary tumor cells, such as WM35 cells, the miR-494 shuttled by exosomes was not obvious. Felicetti $\mathrm{F}$ et al. showed the similar trend, miR-222 was significantly elevated in metastatic melanoma cell exosomes not in primary tumor cell-derived ones [29]. Surely, it is common knowledge that tumor cells with different invasion capacity have different physiological and pathological characteristics [30]. However, the exact cause is unknown, we will further explore this issue in the future. In A375 cells, upregulate miR-494 and decrease exosome release simultaneously significantly inhibits cell proliferative, migration and invasion via promoting cell apoptosis. Conversely, reducing expression of miR-494 in WM35 cells by treating with anti-miR-494 plasmids displayed tumor promoted functions. WM35 cells are thought to be lowly tumorigenic and even non-tumorigenic in nude mice [31,32], Thus only A375 cells were used in nude mice experiments. In animal experiments, exosomal miR-494 was shown to inhibit the both growth and metastasis of melanoma xenografts. These results are more consistent with previous literature, and further provide a new viewpoint for high-metastatic melanoma cells loss miR-494 by exosomal vesicles to maintain or enhance malignancy.

However, there are some limitations in our current study. Other extracellular vesicles and exosomes may not be able to separate by centrifugal force. It would be better to purify EVs from A375 cells by Optiprep density gradients. What's more, some miRNAs have been found to associate with protein complexes and are not be present in EVs. But whether miR-494 is protected by protein complexes or something else is also need to consider. We will further explore this issue in our future work, which may make a new discovery.

\section{CONCLUSIONS}

Consistent with these findings, we demonstrated here that exosomal transfer of miR-494 led to highmetastatic properties of melanoma cells, resulting in promoting proliferation and metastasis in melanoma cells. Thus, exosomal miR-494 may be a promising molecular target for MM therapy.

\section{MATERIALS AND METHODS}

\section{Cell lines and serum samples}

15 case of normal human serum and 15 case of melanoma patients' serum were collected from Third Xiangya Hospital, Central South University. Informed consent was obtained from each patient, and the study was approved by the Ethics Committee of the Third Xiangya Hospital, Central South University. Human primary melanocyte (HEMa-LP) was purchased from XinYu Biological Technology (Shanghai, China). The human melanoma cell line WM35 that was derived from a primary cutaneous melanoma, has no metastasis potential. A375 and WM451 were derived from metastases of malignant melanomas, which were purchased from ATCC (Manassas, VA, USA). Cells were cultured in fresh DMEM/ $10 \%$ FBS medium at $37^{\circ} \mathrm{C}$ with $5 \% \mathrm{CO}_{2}$ in a humidifed atmosphere.

\section{Isolation of exosomes}

Serum was obtained by centrifugation at $400 \mathrm{~g}$, $10 \mathrm{~min}$ at $4^{\circ} \mathrm{C}$. Cell debris were removed by centrifugation at $3,000 \mathrm{~g}, 15 \mathrm{~min}$ at $4^{\circ} \mathrm{C}$ and serum samples were stored at $-20^{\circ} \mathrm{C}$. Upon reaching the appropriate confluency, cells were washed with PBS and incubated with freshly prepared complete medium containing exosome-free FBS for $24 \mathrm{~h}$. For isolating exosomes, conditioned medium was centrifuged at $2,000 \mathrm{~g}\left(4^{\circ} \mathrm{C}\right)$ for $30 \mathrm{~min}$ to remove cells, followed by filtration through a $0.22-\mathrm{mm}$ filter to remove cell debris. Small extracellular vesicles were pelleted by ultracentrifugation at 100,000 g for $70 \mathrm{~min}$. They were resuspended in PBS and collected by ultracentrifugation again at $100,000 \mathrm{~g}$ for $70 \mathrm{~min}$.

\section{Transmission electron microscopy and size distribution}

Exosomes pellets were re-suspended in PBS and fixed with $1 \%$ glutaraldehyde for $5 \mathrm{~min}$. Samples were deposited onto Formvar-carbon-coated electron microscopy grids. The samples were observed using a JEM 1010 transmission electron microscope (JEOL USA, Inc., Peabody, MA) at 80 $\mathrm{kV}$. The size of vesicles was determined by nanoparticle tracking analysis (NTA, Nanosight NS300 system, Malvern Instruments Company, Nanosight, and Malvern, UK). Exosome was diluted of 1:1000 in sterile Phosphate. A size distribution plot was made, with the $\mathrm{x}$-axis showing the distribution of estimated particle radius ( $\mathrm{nm}$ ) and the y-axis showing the relative percentage.

\section{Quantitative real-time RT-PCR}

Total RNA from cells and tissues was extracted with TRIzol reagent (Invitrogen) according to the manufacturer's protocol. Quantitative real-time PCR analyses were performed with MJ mini PCR (MiniOption; 
Bio-Rad Laboratories, CA, USA). For exosomal miR494 expression analysis, $0.5 \mathrm{mg}$ of total RNA was first reverse transcribed using the QuantimiR RT kit (System Biosciences, Camarillo, CA, USA). qRT-PCR analysis was performed using iTaq Universal SYBR green super mix (BioRad Laboratories Inc., Hercules, CA, USA) on a CFX Touch real-time PCR detection system (Bio-Rad Laboratories Inc.). Samples were compared using the relative CT method, where the relative expression of miR-494 was normalized to that of U6. The primers of miR-494 were as follows: forward: GGAGAGGTTGTCCGTGTTGT; reverse: GGCTGC ATC AGG AACAGGAA.

\section{Exosome labeling and cellular uptake}

Exosomes were isolated from the conditioned medium by differential centrifugation following the procedure described above. The protein concentration contained in each exosome pellet was quantified using a Bradford assay (Bio-Rad). Experiments were performed using $50 \mu \mathrm{g}$ of exosomes in each group. Purified exosomes were labeled in some experiments with the green fluorescent linker PKH67 (Sigma-Aldrich) according to the instructions of the manufacturer. The pellet was suspended in serum-free medium and co-cultured with cells grown on cover slips for $24 \mathrm{~h}$. Next, the cells were fixed with $4 \%$ paraformaldehyde. The nuclei were stained with DAPI (blue) and cytoplasm were stained with phalloidine (red), washed with PBS three times and imaged by confocal microscopy (Olympus FV1000, Japan).

\section{Plasmids and transfection}

pLVX-IRES-Zs Green1(No. 632187) lentiviral expression plasmid was bought from Clontech Company, pri-494 and anti-miR-494 was combined to into the plasmid by Yingrun Company (Changsha, China). To inhibit the release of exosomes, three shRNAs target rab27a was constructed and cloned into LV3 (H1/ GFP\&Puro) lentiviral vectors, respectively. The sequences of three shRNA-rab27a were list as follow: sh1-rab27a: 5'-GCAGTTATGGGACACAGCAGG-3', sh2-rab27a: 5'GGATAAGCCAGCTACAGATGC-3', sh3-rab27a: 5'-GC CAATGGGACAAACATAAGC-3'. The transfection efficiency was nearly $100 \%$.

\section{Cell proliferation assay}

Cell viability was assessed by MTT assay. After transfection, $5 \times 10^{3}$ cells/well cells were seeded in 96well plates and cultured for 24, 48 and $96 \mathrm{~h}$, and then the supernatant was removed and MTT $(5 \mathrm{mg} / \mathrm{ml}, 20 \mu \mathrm{l})$ was added to each well at $37^{\circ} \mathrm{C}$. After $4 \mathrm{~h}, 100 \mu \mathrm{LMSO}$ was added to each well. The absorbance at $490 \mathrm{~nm}$ was measured with a plate reader (Thermo Multiskan MK3 spectrophotometer; Thermo Fisher Scientifc, Waltham,
MA, USA). The OD value (at $490 \mathrm{~nm}$ ) was determined and used to construct a growth curve to assess cell proliferation.

\section{Scratch migration and Transwell invasion assays}

Cells were seeded in 24 -well plates $\left(1 \times 10^{5}\right.$ cells/ well) after transfection for $24 \mathrm{~h}$. When cell cultures reached $90 \%$ confluency, a $200 \mu \mathrm{l}$ tip was performed to scratch cell monolayer. Images were captured at different time points ( 0 and $48 \mathrm{~h}$ ) by microscopy to measure gap closure. The migration rate $(\%)$ was calculated using the following formula: migration rate $(\%)=($ Gap $0-$ Gap 48)/Gap0*100. Gap 48 and Gap 0 are the gap width at baseline and $48 \mathrm{~h}$, respectively. Transwell invasion assays were performed to measure the invasive capacity. In brief, cells were plated on $8-\mu \mathrm{m}$ pore size Matrigel-coated membranes $\left(1 \times 10^{5}\right.$ cells/well in $2 \%$ FBS medium $)$, which were in turn placed in the top chamber of 24-well Transwell plates. The bottom chamber contained $500 \mu \mathrm{l}$ $15 \%$ FBS medium. After $24 \mathrm{~h}$, cells on the upper surface were removed, while cells attached to the membranes were fxed in 4\% paraformaldehyde for $20 \mathrm{~min}$ and stained with hematoxylin. The results of the Transwell assay were imaged and the number of invasive cells was evaluated by the resultant OD value $(570 \mathrm{~nm})$.

\section{Western blotting}

Cells were harvested after treatment, and proteins were extracted and then quantifed with a BCA protein assay kit and separated on 10\% SdS-PAGE gels and transferred onto PVDF membranes (Millipore, Billerica, MA, USA). Then, followed standard procedures using rabbit: anti-CD63 (1:1,000, clone RFAC4, EMD Millipore), anti-CD9 (1:1000, Absin, Abs102483) or antiBCL-2 (1:1000, Abcam, ab37899). Immunoreactive bands were visualized by electrochemiluminescence.

\section{Apoptosis analysis}

To detect apoptosis, cells were digested with $0.25 \%$ EDTA-free trypsin and collected by centrifugation at $2,000 \mathrm{rpm}$ for $5 \mathrm{~min}$. After washing with $1 \times \mathrm{PBS}$, $2 \times 10^{5}$ cells were suspended in $500 \mu \mathrm{L}$ of binding buffer. $5 \mu \mathrm{L}$ of annexin V-FITC was then added, followed by the addition of $5 \mu \mathrm{L}$ of propidium iodide, and incubation at room temperature for $10 \mathrm{~min}$ in the dark room. Apoptotic cells were sorted by flow cytometry.

\section{Nude mouse xenograft studies}

All experimental procedures were performed according to NIH Animal Care, and the entire experiment was approved by the Ethics Committee of Faculty of Experimental Animals, Central South University. Male BALB/c-nu/nu (aged 4-6 weeks) were purchased from the animal laboratory of Third Xiangya Hospital of 
Central South University and maintained under specifc pathogen free conditions. 20 nude mice were injected subcutaneously in the ventral trunk with $2 \times 10^{6}$ cells in $200 \mu \mathrm{l}$ DMEM, respectively. Tumor volume was calculated using the formula $\mathrm{V}\left(\mathrm{mm}^{3}\right)=0.5 \times \mathrm{a} \times \mathrm{b}^{2}$, where $\mathrm{a}$ is the maximum length to diameter; $\mathrm{b}$ is the maximum transverse diameter. Nude mice were sacrifced at 42 days after tumor implantation, and tumor volume and weight were measured.

A TUNEL assay was performed to measure tumor cells. Mixture of TdT and dUTP was add to tumor tissues at $37^{\circ} \mathrm{C}$ for $120 \mathrm{~min}$. Then, converter-POD was added at $37^{\circ} \mathrm{C}$ for $30 \mathrm{~min}$. Following incubation, excess labelling solution is washed off with PBS and the chromatin of apoptotic cell were visualized using DAB. Sections were then counterstained with hematoxylin. Normal nuclei was detected as blue and nuclei with damaged DNA was seen as brown.

To evaluate metastasis of tumor cells, suspended cells $\left(1 \times 10^{6} / 0.2 \mathrm{~mL}\right)$ were injected into the lateral tail vein of nude mice. They were sacrificed 8 weeks after inoculation or when they became moribund, and the lungs were excised and fixed in 4\% buffered formaldehyde for $24 \mathrm{~h}$. The tissues were embedded in paraffin and stained with haematoxylin and eosin (H.E.) for histologic examination.

\section{Statistical analysis}

All experiments were repeated at least three times, and the results are expressed as the mean $\pm \mathrm{SD}(n=3)$. Briefly, statistical analyses were carried out using SPSS 19.0 software (SPSS, Chicago, IL, USA). The results were assessed by Student's $t$-test. All statistical tests were twosided, and a $P$-value of $<0.05$ was considered to indicate a statistically signifcant difference, ${ }^{*} P<0.05$.

\section{Author contributions}

Jianda Zhou and Ke Cao designed the experiments and drafted the manuscript. Jingjing Li and Jian Chen performed the experiments. Shaohua Wang, Ping Li and Changli Zheng participated in the design of the study and collected clinical samples. Shijie Tang, Xiao Zhou, Yongguang Tao and Xiang Chen supervised all of the work and revised the manuscript. Linchun Sun and Aijun Wang performed the statistical analysis. All of the authors have read and approved the final manuscript.

\section{ACKNOWLEDGMENTS AND FUNDING}

This work was supported by the National Natural Science Foundation of China (No. 81372140, 81572689, 81572965), Program for New Century Excellent Talents in University (No. NCET-11-0527), the Innovation-Driven Project of Central South University (No. 2017CX012), 125 Talent Project/New xiangya project of the Third Xiangya Hospital of Central South University; Fundamental
Research Funds for the Central Universities of Central South University (No. 2017zzts220).

\section{CONFLICTS OF INTEREST}

The authors declare that they have no conflicts of interest.

\section{REFERENCES}

1. Xie B, Cao K, Li J, Chen J, Tang J, Chen X, Xia K, Zhou X, Cheng Y, Zhou J, Xie H. Hmgb1 inhibits Klotho expression and malignant phenotype in melanoma cells by activating NF-кB. Oncotarget. 2016; 7:80765-80782. https://doi. org/10.18632/oncotarget.12623.

2. Sucker A, Zhao F, Pieper N, Heeke C, Maltaner R, Stadtler N, Real B, Bielefeld N, Howe S, Weide B, Gutzmer R, Utikal J, Loquai $\mathrm{C}$, et al. Acquired IFN $\gamma$ resistance impairs anti-tumor immunity and gives rise to T-cell-resistant melanoma lesions. Nat Commun. 2017; 8:15440-15454.

3. Linos E, Swetter SM, Cockburn MG, Colditz GA, Clarke CA. Increasing burden of melanoma in the United States. J Invest Dermatol. 2009; 129:1666-1674.

4. Strickland LR, Pal HC, Elmets CA, Afaq F. Targeting drivers of melanoma with synthetic small molecules and phytochemicals. Cancer Lett. 2015; 359:20-35.

5. Gray-Schopfer V, Wellbrock C, Marais R. Melanoma biology and new targeted therapy. Nature. 2007; 445:851-857.

6. Scudellari M. Drug development: try and try again. Nature. 2014; 516:S4-6.

7. Ambros V. The functions of animal microRNAs. Nature. 2004; 431:350-355.

8. Zhou Y, Huang Z, Wu S, Zang X, Liu M, Shi J. miR-33a is up-regulated in chemoresistant osteosarcoma and promotes osteosarcoma cell resistance to cisplatin by down-regulating TWIST. J Exp Clin Cancer Res. 2014; 33:12-23.

9. Zhou J, Xu D, Xie H, Tang J, Liu R, Li J, Wang S, Chen X, Su J, Zhou X, Xia K, He Q, Chen J, et al. miR-33a functions as a tumor suppressor in melanoma by targeting HIF-1 $\alpha$. Cancer Biol Ther. 2015; 16:846-855.

10. Xu D, Tan J, Zhou M, Jiang B, Xie H, Nie X, Xia K, Zhou J. Let-7b and microRNA-199a inhibit the proliferation of B16F10 melanoma cells. Oncol Lett. 2012; 4:941-946.

11. Chen Y, Zhang Z, Luo C, Chen Z, Zhou J. MicroRNA-18b inhibits the growth of malignant melanoma via inhibition of HIF-1 $\alpha$-mediated glycolysis. Oncol Rep. 2016; 36:471-479.

12. Chen Y, Cao KE, Wang S, Chen J, He B, He GU, Chen Y, Peng B, Zhou J. MicroRNA-138 suppresses proliferation, invasion and glycolysis in malignant melanoma cells by targeting HIF-1 $\alpha$. Exp Ther Med. 2016; 11:2513-2518.

13. Zhang L, Zhang S, Yao J, Lowery FJ, Zhang Q, Huang WC, Li P, Li M, Wang X, Zhang C, Wang H, Ellis K, Cheerathodi $\mathrm{M}$, et al. Microenvironment-induced PTEN 
loss by exosomal microRNA primes brain metastasis outgrowth. Nature. 2015; 527:100-104.

14. Cvjetkovic A, Lötvall J, Lässer C. The influence of rotor type and centrifugation time on the yield and purity of extracellular vesicles. J Extracell Vesicles. 2014; 3:3-13.

15. Melo SA, Luecke LB, Kahlert C, Fernandez AF, Gammon ST, Kaye J, LeBleu VS, Mittendorf EA, Weitz J, Rahbari N, Reissfelder C, Pilarsky C, Fraga MF, et al. Glypican-1 identifies cancer exosomes and detects early pancreatic cancer. Nature. 2015; 523:177-182.

16. Au Yeung CL, Co NN, Tsuruga T, Yeung TL, Kwan SY, Leung CS, Li Y, Lu ES, Kwan K, Wong KK, Schmandt R, Lu KH, Mok SC. Exosomal transfer of stroma-derived miR21 confers paclitaxel resistance in ovarian cancer cells through targeting APAF1. Nat Commun. 2016; 7:11150-11163.

17. Peinado H, Alečković M, Lavotshkin S, Matei I, Costa-Silva B, Moreno-Bueno G, Hergueta-Redondo M, Williams C, García-Santos G, Ghajar C, Nitadori-Hoshino A, Hoffman C, Badal K, et al. Melanoma exosomes educate bone marrow progenitor cells toward a pro-metastatic phenotype through MET. Nat Med. 2012; 18:883-891.

18. Hou X, Wan W, Wang J, Li M, Wang Y, Yao Y, Feng L, Jing L, Lu H, Jia Y, Peng T. Let-7a inhibits migration of melanoma cells via down-regulation of HMGA2 expression. Am J Transl Res. 2016; 8:3656-3665.

19. Li J, Chen Y, Guo X, Zhou L, Jia Z, Peng Z, Tang Y, Liu W, Zhu B, Wang L, Ren C. GPC1 exosome and its regulatory miRNAs are specific markers for the detection and target therapy of colorectal cancer. J Cell Mol Med. 2017; 21:838-847.

20. Romano G, Acunzo M, Garofalo M, Di Leva G, Cascione L, Zanca C, Bolon B, Condorelli G, Croce CM. MiR494 is regulated by ERK1/2 and modulates TRAILinduced apoptosis in non-small-cell lung cancer through BIM down-regulation. Proc Natl Acad Sci U S A. 2012; 109:16570-16575.

21. Teng Y, Ren Y, Hu X, Mu J, Samykutty A, Zhuang X, Deng Z, Kumar A, Zhang L, Merchant ML, Yan J, Miller DM, Zhang HG. MVP-mediated exosomal sorting of miR-193a promotes colon cancer progression. Nat Commun. 2017; 8:14448-14463.

22. Tamkovich SN, Yunusova NV, Stakheeva MN, Somov AK, Frolova AY, Kirushina NA, Afanasyev SG, Grigoryeva AE, Laktionov PP, Kondakova IV. [Isolation and characterization of exosomes from blood plasma of breast cancer and colorectal cancer patients]. [Article in Russian]. Biomed Khim. 2017; 63:165-69.

23. Skog J, Würdinger T, van Rijn S, Meijer DH, Gainche L, Sena-Esteves M, Curry WT Jr, Carter BS, Krichevsky AM,
Breakefield XO. Glioblastoma microvesicles transport RNA and proteins that promote tumour growth and provide diagnostic biomarkers. Nat Cell Biol. 2008; 10:1470-1476.

24. Xu Y, Liu Y, Yang C, Kang L, Wang M, Hu J, He H, Song W, Tang H. Macrophages transfer antigens to dendritic cells by releasing exosomes containing dead-cell-associated antigens partially through a ceramide-dependent pathway to enhance CD4(+) T-cell responses. Immunology. 2016; 149:157-171.

25. Xiao D, Barry S, Kmetz D, Egger M, Pan J, Rai SN, Qu J, McMasters KM, Hao H. Melanoma cell-derived exosomes promote epithelial-mesenchymal transition in primary melanocytes through paracrine/autocrine signaling in the tumor microenvironment. Cancer Lett. 2016; 376:318-327.

26. Romano G, Kwong LN. miRNAs, Melanoma and Microenvironment: An Intricate Network. Int J Mol Sci. 2017; 18:E2354-69.

27. Alegre E, Sanmamed MF, Rodriguez C, Carranza O, Martín-Algarra S, González A. Study of circulating microRNA-125b levels in serum exosomes in advanced melanoma. Arch Pathol Lab Med. 2014; 138:828-832.

28. Chi MN, Guo ST, Wilmott JS, Guo XY, Yan XG, Wang CY, Liu XY, Jin L, Tseng HY, Liu T, Croft A, Hondermarck H, Scolyer RA, et al. INPP4B is upregulated and functions as an oncogenic driver through SGK3 in a subset of melanomas. Oncotarget. 2015; 6:39891-907. https://doi. org/10.18632/oncotarget.5359.

29. Felicetti F, De Feo A, Coscia C, Puglisi R, Pedini F, Pasqunini L, Bellenghi M, Errico MC, Pagani E, Carè A. Exosome-mediated transfer of miR-222 is sufficient to increase tumor malignancy in melanoma. J Transl Med. 2016; 14:56-70.

30. Kramer RH, $\mathrm{Vu} \mathrm{M}$, Cheng YF, Ramos DM. Integrin expression in malignant melanoma. Cancer Metastasis Rev. 1991; 10:49-59.

31. Cao K, Li J, Chen J, Qian L, Wang A, Chen X, Xiong W, Tang J, Tang S, Chen Y, Chen Y, Cheng Y, Zhou J. microRNA-33a-5p increases radiosensitivity by inhibiting glycolysis in melanoma. Oncotarget. 2017; 8:83660-83672. https://doi.org/10.18632/oncotarget.19014.

32. Massari NA, Medina VA, Cricco GP, Martinel Lamas DJ, Sambuco L, Pagotto R, Ventura C, Ciraolo PJ, Pignataro O, Bergoc RM, Rivera ES. Antitumor activity of histamine and clozapine in a mouse experimental model of human melanoma. J Dermatol Sci. 2013; 72:252-262. 